\title{
Adherence to prescription guidelines and achievement of treatment goals among persons with coronary heart disease in Tromsø 7
}

Elisabeth Pedersen ${ }^{* *}$, B Beate Hennie Garcia ${ }^{1}$, Kjell H. Halvorsen ${ }^{1}$, Anne Elise Eggen ${ }^{2}$, Henrik Schirmer ${ }^{3,4}$ and Marit Waaseth ${ }^{1}$

\begin{abstract}
Background: Adherence to clinical practice guidelines for coronary heart disease (CHD) reduces morbidity, mortality and treatment costs. We aimed to describe and compare adherence to prescription guidelines for persons with CHD, and explore its association with treatment goal achievement.

Method: We included all participants reporting myocardial infarction, angina, percutaneous coronary intervention and/or coronary artery bypass surgery in the seventh wave of the Troms $\varnothing$ Study $(2015-2016, n=1483)$. Medication use and treatment goal measures (blood pressure, low-density lipoprotein (LDL)-cholesterol and HbA1c) were compared to clinical practice guidelines on secondary CHD prevention. Propensity score matched logistic regression was used to assess the association between the use of antihypertensive drugs and achievement of treatment goal for blood pressure, and the use of lipid-lowering drugs (LLDs) and achievement of treatment goal for LDL-cholesterol.

Results: The prevalence of pharmacological CHD treatment was $76 \%$ for LLDs, $72 \%$ for antihypertensive drugs and $66 \%$ for acetylsalicylic acid. The blood pressure goal $(<140 / 90 \mathrm{mmHg},<140 / 80 \mathrm{mmHg}$ if diabetic) was achieved by $58 \%$ and the LDL-cholesterol goal $(<1.8 \mathrm{mmol} / \mathrm{l}$ or $<70 \mathrm{mg} / \mathrm{dL}$ ) by $9 \%$. There was a strong association between using LLDs and achieving the treatment goal for LDL-cholesterol (OR 14.0, 95\% Cl 3.6-54.7), but not between using antihypertensive drugs and blood pressure goal achievement (OR 1.4, 95\% Cl 0.7-2.7).

Conclusion: Treatment goal achievement of LDL-cholesterol and blood pressure was low, despite the relatively high use of LLDs and antihypertensive drugs. Further research is needed to find the proper actions to increase achievement of the treatment goals.
\end{abstract}

Keywords: Coronary heart disease, Prescription guidelines, Blood pressure, Antihypertensive agents, Lipid-lowering drugs, Low-density lipoprotein (LDL)-cholesterol

*Correspondence: elisabeth.pedersen@uit.no

${ }^{1}$ Department of Pharmacy, UiT The Arctic University of Norway, Tromsø, Norway

Full list of author information is available at the end of the article

\section{Background}

Coronary heart disease (CHD) is one of the leading causes of deaths worldwide and a common cause of hospital admissions $[1,2]$. The major modifiable risk factors are high blood pressure and cholesterol levels, tobacco smoking, diabetes mellitus, low physical activity, obesity, and unhealthy diet [3]. Over the recent decades, 
the world has witnessed a substantial reduction in CHD morbidity and mortality which is partially attributed to strategies based on lowering of blood pressure and cholesterol, as well as successful acute treatment $[4,5]$.

Clinical practice guidelines for CHD promote risk factor reduction, both in terms of lifestyle changes and medication use. Lipid-lowering drugs (LLDs), antihypertensive drugs and acetylsalicylic acid (ASA) comprise the recommended secondary prevention after both myocardial infarction (MI) and coronary artery intervention like percutaneous coronary intervention (PCI) or coronary artery bypass surgery (CABG) [6]. Adherence to these prescription guidelines has been shown to prevent premature mortality, reduce morbidity and healthcare costs, and improve the patient's quality of life [6].

The European survey of cardiovascular disease prevention and diabetes (EUROASPIRE) is the largest European CHD survey, and it has evaluated the implementation of clinical guidelines in CHD patients five times since 19951996 [7]. The most recent EUROASPIRE survey showed that $>80 \%$ of $\mathrm{CHD}$ patients use antihypertensive drugs and LLDs. The survey also showed that achievement of the recommended treatment goals is low, where $58 \%$ of the patients reach the treatment goal for blood pressure and $29 \%$ the treatment goal for low-density lipoprotein (LDL)-cholesterol. Similar results have also been found in a Norwegian study, where $93 \%$ used both antihypertensive drugs and LLDs, while $54 \%$ reached the treatment goal for blood pressure and $43 \%$ reached the treatment goal for LDL-cholesterol [8].

Studies have shown an increase in treatment goal achievement in line with a decrease in blood pressure and cholesterol in the general population [9-13], but mainly describe adherence to clinical prescription guidelines and treatment goal achievement on an aggregated and not an individual level. Associations between treatment goal achievement and adherence to guidelines concerning prescription have also not been explored.

The aim of this study was to describe and compare adherence to prescription guidelines for persons with $\mathrm{CHD}$ and explore its association with treatment goal achievement for blood pressure and LDL-cholesterol.

\section{Methods}

\section{Study setting and study population}

The Tromsø Study is a Norwegian population-based epidemiological health study that has been conducted seven times from 1974 to 2016 [14]. The population of the Troms $\varnothing$ Study consists of inhabitants in the municipality of Tromsø in North Norway, a university town with approximately 70000 inhabitants, and it is considered representative for a white, urban Northern European population [15].

The current study is a cross-sectional study applying data collected from participants in the seventh wave of the Tromsø Study (Tromsø 7). Tromsø 7 was conducted in 2015 and 2016 and invited all inhabitants in the municipality aged 40 years or older $(\mathrm{n}=32,591)$ to participate. Response rate was $65 \%(n=21,083)$. Participants answered several questionnaires, donated blood samples and went through a range of anthropometric measurements (height, weight, body circumferences and clinical examinations). Links to the questionnaires can be found at the Tromsø Study's webpage [16]. We included persons who self-reported CHD in the mandatory questionnaire, i.e. previous MI, present or previous angina pectoris (AP) and/or previous PCI or CABG. Participants with selfreported diabetes or reporting use of antidiabetic drugs and those with self-reported hypertension were defined as subgroups in some analyses.

We included a total of 1483 (7.0\%) participants with CHD; 753 with previous MI, 466 with AP and 1226 with previous PCI and/or CABG, some of them indicating more than one disease (Fig. 1). We divided our study population into three subgroups; previous MI $(\mathrm{n}=753)$, PCI or CABG but no previous MI $(\mathrm{n}=604)$ and only AP with no previous MI, PCI or CABG $(n=126)$. Of the 1483 participants with CHD, 214 (14\%) had diabetes, and 827 (56\%) reported having hypertension.

\section{Data extraction}

We extracted information about blood pressure measurements from clinical examinations, LDL-cholesterol and HbA1c from blood samples and self-reported data from questionnaires. The questionnaire data included information about present and previous diseases, medication use, health concerns, use of health services, diet, physical activity, smoking status, alcohol consumption and socio-demography.

Prevalent users of LLDs, antihypertensive drugs and antidiabetic drugs were defined by two approaches; (1) by including those who replied "currently" when asked "Do you use, or have you used cholesterol lowering drugs/ blood pressure lowering drugs/insulin or tablets for diabetes?" (answering options were "currently", "previously, not now" and "never used") or (2) mentioning the brand name of medications within these drug classes when asked to write down the brand names for all medications used regularly during the previous four weeks. Prevalent ASA use was defined as answering "yes" when asked "If you have used analgesics and anti-inflammatory medication regularly in the past year-did you use "Baby" or low dose acetylsalicylic acid (ASA) Acetylsalisylsyre ${ }^{\circledR}$ Albyl- $E^{\circledR}$ Asasantin Retard ${ }^{\circledR}$ (75/160 mg per tablet)?" (answering 


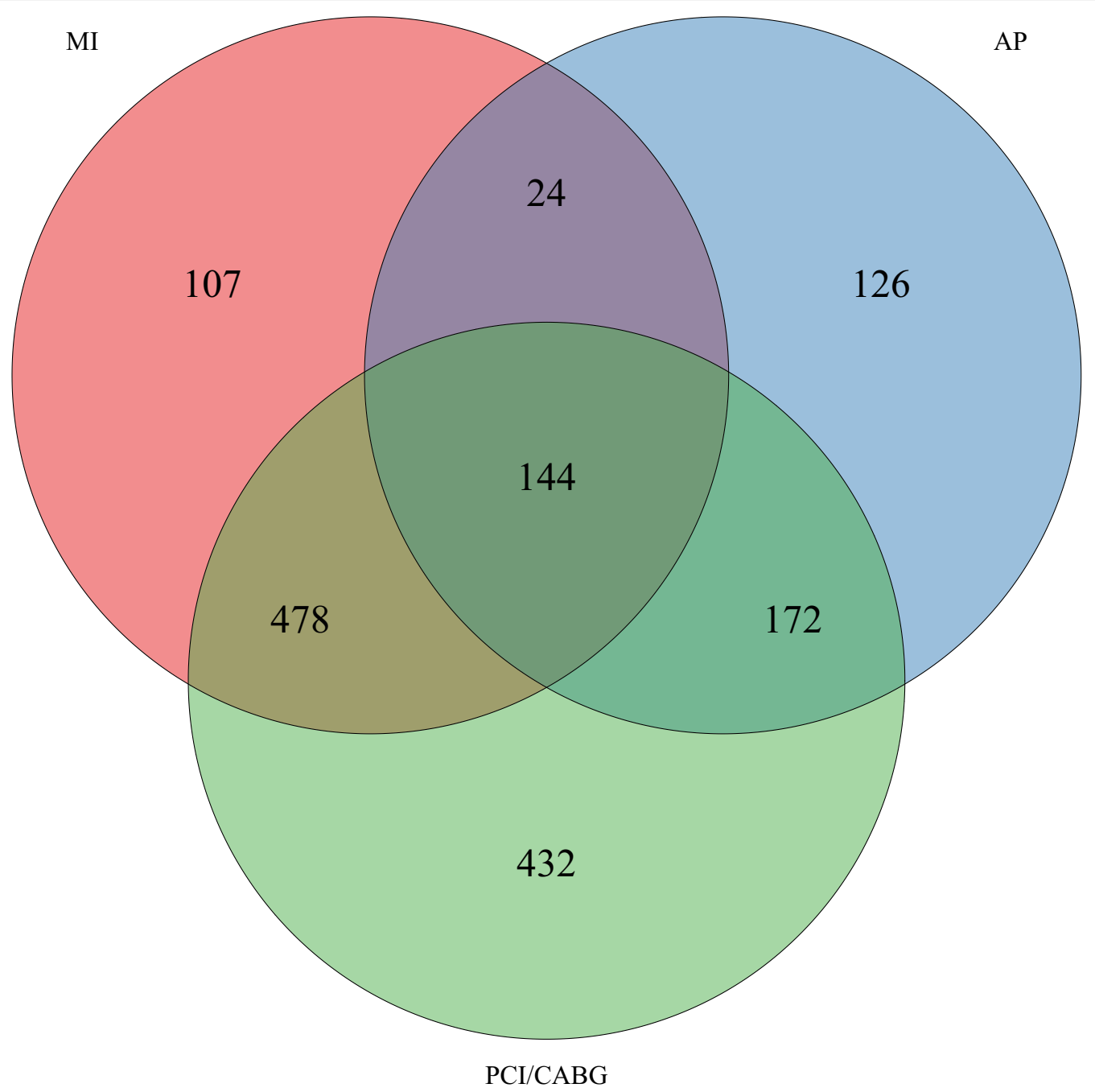

Fig. 1 Distribution of participants across coronary heart disease groups in Troms $\varnothing 7$. AP, angina pectoris; CABG, coronary artery bypass surgery; MI, myocardial infarction; $\mathrm{PCl}$, percutaneous coronary intervention

options were "yes" and "no"), or mentioning a brand name for ASA when asked to write down brand names for all the medications used regularly during the previous four weeks.

Brand names were recoded by trained personnel using the anatomical therapeutic chemical (ATC) classification system and categorised into medication groups. LLDs included statins and other LLDs. Antihypertensive drugs included angiotensin converting enzyme (ACE) inhibitors, angiotensin receptor blockers (ARBs), beta-blockers, calcium channel blockers (CCBs), thiazides, other diuretics and other antihypertensives (Additional file 1: Table S1).

In Tromsø 7, blood pressure was measured with an automated digital device (Dinamap ProCare 300 monitor, GE Healthcare, Norway) [9]. Three consecutive measurements were taken. Blood pressure was defined as the mean of the last two measurements. If only the third measurement was missing $(n=2)$, the second measurement was used. When both the second and third measurement, but not the first, was missing $(n=1)$, the first measurement was used. LDLcholesterol was collected and analyzed by trained personnel using enzymatic colorimetric methods with commercial kits on a Cobas 8000 c702 (Roche Diagnostics $\mathrm{GmbH}$, Mannheim, Germany) from non-fasting venous blood samples. The analysis was performed at the Department of Laboratory Medicine, University Hospital of North Norway, Tromsø, Norway (ISO certification NS-EN ISO 15189:2012) [10]. 
Treatment goal achievement and medication use were assessed based on the European Guidelines on cardiovascular disease prevention in clinical practice from 2012 (Table 1) [6]. At the time of data collection, there were no Norwegian clinical guidelines for secondary prevention of CHD.

\section{Statistical method}

Descriptive statistics are presented as frequencies with proportions (\%) (categorical variables) and means with standard deviation (SD) (continuous variables).

Chi square tests were used to examine the relationship between achievement of treatment goals for blood pressure and LDL-cholesterol and use of LLDs, antihypertensive drugs and ASA, and between achievement of treatment goals and disease group. Significance level was set to $5 \%$.

Logistic regression was used to explore the association between use of antihypertensive drugs and achievement of treatment goal for blood pressure, as well as the association between use of LLDs and achievement of treatment goal for LDL-cholesterol. Participants with missing measurements for blood pressure $(n=3)$ and LDL-cholesterol $(n=11)$ were excluded from the respective analyses. Propensity score matching was used to control for confounding from covariates including age, sex, body mass index (BMI), relevant comorbidities, diet, physical activity, use of health services, alcohol consumption and smoking (including use of smokeless tobacco) (for more information about the variables included, see Additional file 1: Table S2). The matching method used was nearest neighbour matching, and the procedure was performed with replacement and a caliper of 0.2 .

Due to the high proportion of missing values in some of the covariates, imputation was needed to perform the analyses. If a factor was described by more than one variable (e.g. use of health services, tobacco, alcohol), these variables were combined. For instance, a participant reporting current smoking on at least one question regarding smoking habits would be categorised as a smoker. Multiple imputation by chained equations was then performed using the $\mathrm{R}$ packages mice and MatchIt.mice (see Additional file 1: Table S3 for variables included). Predictive mean matching was used to impute numeric variables, logistic regression for binary categorical variables, proportional odds model for ordered categorical variables and polytomous logistic regression for unordered categorical variables. Ten imputated datasets where created with 50 iterations. The analyses were then performed with the within approach, which means that the propensity score matching and logistic regression was performed in each imputed dataset and the results subsequently pooled together to an overall result. We used the non-imputed dataset for the descriptive analyses and chi square tests, and the imputed datasets for the regression analyses.

All descriptive statistical analyses were performed using SPSS version 25.0 (IBM Corp, 2017). Chi square tests, multiple imputation, propensity score matching and logistic regression were conducted using $R$ ( $R$ Core

Table 1 Recommendations in guidelines on cardiovascular disease prevention by the European Society of Cardiology in 2012 [6]

\begin{tabular}{l} 
Medication prescription \\
\hline Acetylsalicylic acid \\
Lipid-lowering drugs \\
Statins \\
Antihypertensive drugs (if hypertension) \\
ACE inhibitor/ARB (first choice for diabetics) \\
Beta-blockers \\
Calcium channel blockers \\
Diuretics \\
\hline Treatment goals \\
\hline Blood pressure \\
$<140 / 90 \mathrm{mmHg}(<140 / 80 \mathrm{mmHg}$ if diabetic) \\
LDL-cholesterol \\
$<1.8 \mathrm{mmol} / \mathrm{l}(<70 \mathrm{mg} / \mathrm{dL})$ \\
$\mathrm{HbA1C}$ (if diabetic) \\
$<7 \%$
\end{tabular}

ACE, angiotensin converting enzyme; ARB, angiotensin receptor blocker; HbA1c, glycated haemoglobin; LDL, low-density lipoprotein 
Team (2019). R: A language and environment for statistical computing. R Foundation for Statistical Computing, Vienna, Austria. URL https://www.R-project.org/).

\section{Ethics}

The study was approved by the Norwegian Data Protection Authority and the Regional Committee for Medical and Health Research Ethics of North Norway. All participants in the Tromsø Study have given written informed consent for their data to be used in research.

\section{Results}

The basic characteristics of the study population and across the three CHD disease groups are shown in Table 2.

Use of medications for CHD was highest among participants with previous MI and lowest among those with AP only, see Fig. 2. Of those with hypertension $(n=827)$, $92 \%$ used antihypertensive drugs. Among users of antihypertensive drugs, the drug classes included beta-blockers (63\%), ACE-inhibitors or ARBs (49\%), CCBs (22\%), thiazides (16\%), other (17\%) and unknown (9\%) antihypertensive drugs (for ATC-classification of medication

Table 2 Characteristics of the study population

\begin{tabular}{|c|c|c|c|c|c|c|c|c|}
\hline \multirow{2}{*}{ Sex, n (\%) } & \multicolumn{2}{|c|}{$\begin{array}{l}\text { Total CHD population } \\
(n=1483)\end{array}$} & \multicolumn{2}{|c|}{$\begin{array}{l}\text { MI } \\
(n=753)\end{array}$} & \multicolumn{2}{|c|}{$\begin{array}{l}\mathrm{PCl} \text { and/or CABG, but } \\
\text { no } \mathrm{MI} \\
(\mathrm{n}=604)\end{array}$} & \multicolumn{2}{|c|}{$\begin{array}{l}\text { AP, but no MI, } \\
\text { PCl or CABG } \\
(n=126)\end{array}$} \\
\hline & & & & & & & & \\
\hline Women & 446 & $(30.1)$ & 174 & $(23.1)$ & 203 & (33.6) & 69 & $(54.8)$ \\
\hline Age, mean (sd) & 68.7 & $(10.8)$ & 69.2 & $(10.1)$ & 69.2 & $(10.6)$ & 63.0 & (13.7) \\
\hline \multicolumn{9}{|l|}{ Smoking, n (\%) } \\
\hline Daily smoking & 182 & $(12.3)$ & 96 & $(12.7)$ & 67 & $(11.1)$ & 19 & $(15.1)$ \\
\hline Smoked previously & 860 & $(58.0)$ & 472 & $(62.7)$ & 334 & $(55.3)$ & 54 & $(42.9)$ \\
\hline \multicolumn{9}{|l|}{ Self-reported health, n (\%) } \\
\hline Excellent/good & 705 & $(47.5)$ & 343 & $(45.6)$ & 311 & $(51.5)$ & 51 & $(40.5)$ \\
\hline Neither good nor bad & 602 & $(40.6)$ & 318 & $(42.2)$ & 232 & $(38.4)$ & 52 & $(41.3)$ \\
\hline Bad/very bad & 153 & $(10.3)$ & 79 & $(10.5)$ & 53 & $(8.8)$ & 21 & $(16.7)$ \\
\hline \multicolumn{9}{|l|}{ Comorbidities*, n (\%) } \\
\hline Hypertension & 827 & $(55.8)$ & 433 & $(57.5)$ & 328 & $(54.3)$ & 66 & $(52.4)$ \\
\hline Heart failure & 231 & $(15.6)$ & 126 & $(16.7)$ & 94 & $(15.6)$ & 11 & $(8.7)$ \\
\hline Atrial fibrillation & 283 & $(19.1)$ & 138 & $(18.3)$ & 111 & $(18.4)$ & 34 & $(27.0)$ \\
\hline Stroke & 123 & $(8.3)$ & 65 & $(8.6)$ & 49 & $(8.1)$ & 9 & $(7.1)$ \\
\hline Diabetes & 214 & $(14.4)$ & 123 & $(16.3)$ & 80 & $(13.2)$ & 11 & $(8.7)$ \\
\hline Renal disease & 114 & $(7.7)$ & 68 & $(9.0)$ & 35 & $(5.6)$ & 11 & $(8.7)$ \\
\hline Cancer & 189 & $(12.7)$ & 101 & $(13.4)$ & 77 & $(12.7)$ & 11 & (8.7) \\
\hline Medications, mean number of products (sd) & 4.0 & $(2.9)$ & 4.3 & $(3.0)$ & 3.8 & $(2.8)$ & 3.0 & $(2.9)$ \\
\hline \multicolumn{9}{|l|}{ Clinical measurements, mean (sd) } \\
\hline Systolic blood pressure, mmHg & 136 & $(20.9)$ & 135 & $(21.7)$ & 137 & $(19.9)$ & 133 & $(20.3)$ \\
\hline Diastolic blood pressure, $\mathrm{mmHg}$ & 74 & $(9.9)$ & 75 & $(10.0)$ & 74 & $(9.6)$ & 76 & $(10.1)$ \\
\hline Total cholesterol, $\mathrm{mmol} / \mathrm{l}^{+}$ & 4.6 & $(1.1)$ & 4.5 & $(1.1)$ & 4.7 & $(1.1)$ & 5.6 & $(1.3)$ \\
\hline LDL-cholesterol, mmol/// & 2.9 & $(1.0)$ & 2.7 & $(1.0)$ & 2.9 & $(1.0)$ & 3.7 & $(1.2)$ \\
\hline $\mathrm{HDL}$-cholesterol, $\mathrm{mmol} / \mathrm{I}^{\dagger}$ & 1.4 & $(0.4)$ & 1.4 & $(0.4)$ & 1.5 & $(0.5)$ & 1.5 & $(0.4)$ \\
\hline Triglycerides, mmol// $\mathrm{I}^{\ddagger}$ & 1.6 & $(1.0)$ & 1.7 & $(1.0)$ & 1.5 & $(0.8)$ & 1.8 & (0.9) \\
\hline $\mathrm{HbA} 1 \mathrm{c}, \%$ & 6.1 & $(0.9)$ & 6.1 & $(1.0)$ & 6.0 & $(0.8)$ & 5.8 & $(0.5)$ \\
\hline Glucose, $\mathrm{mmol} / \mathrm{l}^{\S}$ & 6.0 & $(2.1)$ & 6.2 & $(2.3)$ & 6.0 & (1.9) & 5.6 & (1.3) \\
\hline $\mathrm{BMI}, \mathrm{kg} / \mathrm{m}^{2}$ & 28.4 & $(4.5)$ & 28.5 & $(4.4)$ & 28.1 & $(4.4)$ & 28.7 & (5.2) \\
\hline
\end{tabular}

$A P$, angina pectoris; $B M I$, body mass index; $C A B G$, coronary artery bypass graft; $C H D$, coronary heart disease; $H D L$, high-density lipoprotein; $L D L$, low-density lipoprotein; Ml, myocardial infarction; $\mathrm{PCl}$, percutaneous coronary intervention; sd, standard deviation

"Self-reported relevant comorbidities for coronary heart disease, present or previous diseases. For diabetes: present disease or use of any antidiabetic drug

${ }^{\dagger}$ To convert to $\mathrm{mg} / \mathrm{dL}$, multiply with 38.67

${ }^{\ddagger}$ To convert to $\mathrm{mg} / \mathrm{dL}$, multiply with 88.57

${ }^{\S}$ To convert to $\mathrm{mg} / \mathrm{dL}$, multiply with 18.02 


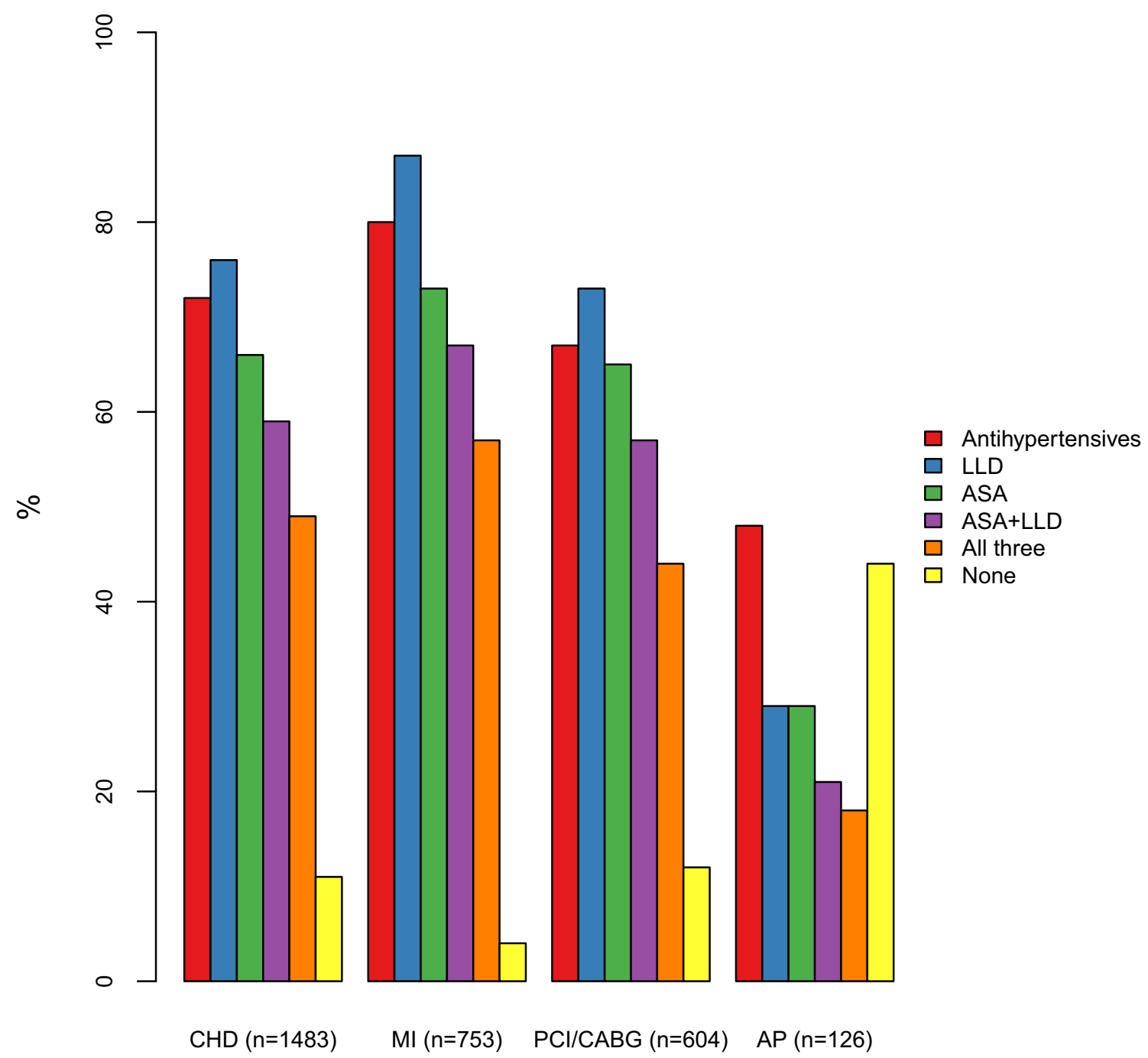

Fig. 2 Proportion of participants using medications for $C H D$ in total and across the CHD disease groups. AP, angina pectoris; ASA, acetylsalicylic acid; CABG, coronary artery bypass surgery; CHD, coronary heart disease; LLD, lipid-lowering drug; MI, myocardial infarction; PCl, percutaneous coronary intervention

groups, see Additional file 1: Table S1). Fifty-one percent used two or more medications from different antihypertensive drug classes. The most frequent class of LLD was statins (79\% of LLD users), while $20 \%$ did not report which LLD they used. As $98 \%$ of those using LLDs in Norway use statins [17], these were assumed to be statin users. Among the LLD-users, 3\% used another LLD in combination with a statin, while $1 \%$ used another LLD, but not a statin.

Blood pressure goal achievement $(<140 / 90 \mathrm{mmHg},<140 / 80 \mathrm{mmHg}$ in persons with diabetes) was highest among those with AP only and lowest among those without MI but previous PCI or CABG, see Fig. 3a. Among those reporting having hypertension,
49\% reached the treatment goal for blood pressure. For comparison, Fig. 3a also includes the proportion having a blood pressure $<150 / 90 \mathrm{mmHg}$.

LDL-cholesterol goal achievement $\quad(<1.8 \mathrm{mmol} / \mathrm{l}$ or $<70 \mathrm{mg} / \mathrm{dL}$ ) was highest among those with previous MI and lowest among those with AP only, see Fig. 3b. For comparison, Fig. 3b also includes the proportions having LDL-cholesterol $<2.5 \mathrm{mmol} / \mathrm{L} \quad(<97 \mathrm{mg} / \mathrm{dL})$ and $<3.0 \mathrm{mmol} / \mathrm{L}(<116 \mathrm{mg} / \mathrm{dL})$, the recommended treatment goals for persons at high and moderate risk of CHD respectively.

Thirty-eight percent of the study population did not reach any of the two treatment goals and $6 \%$ reached both (Fig. 3c). In the study population, $5 \%$ were completely in 


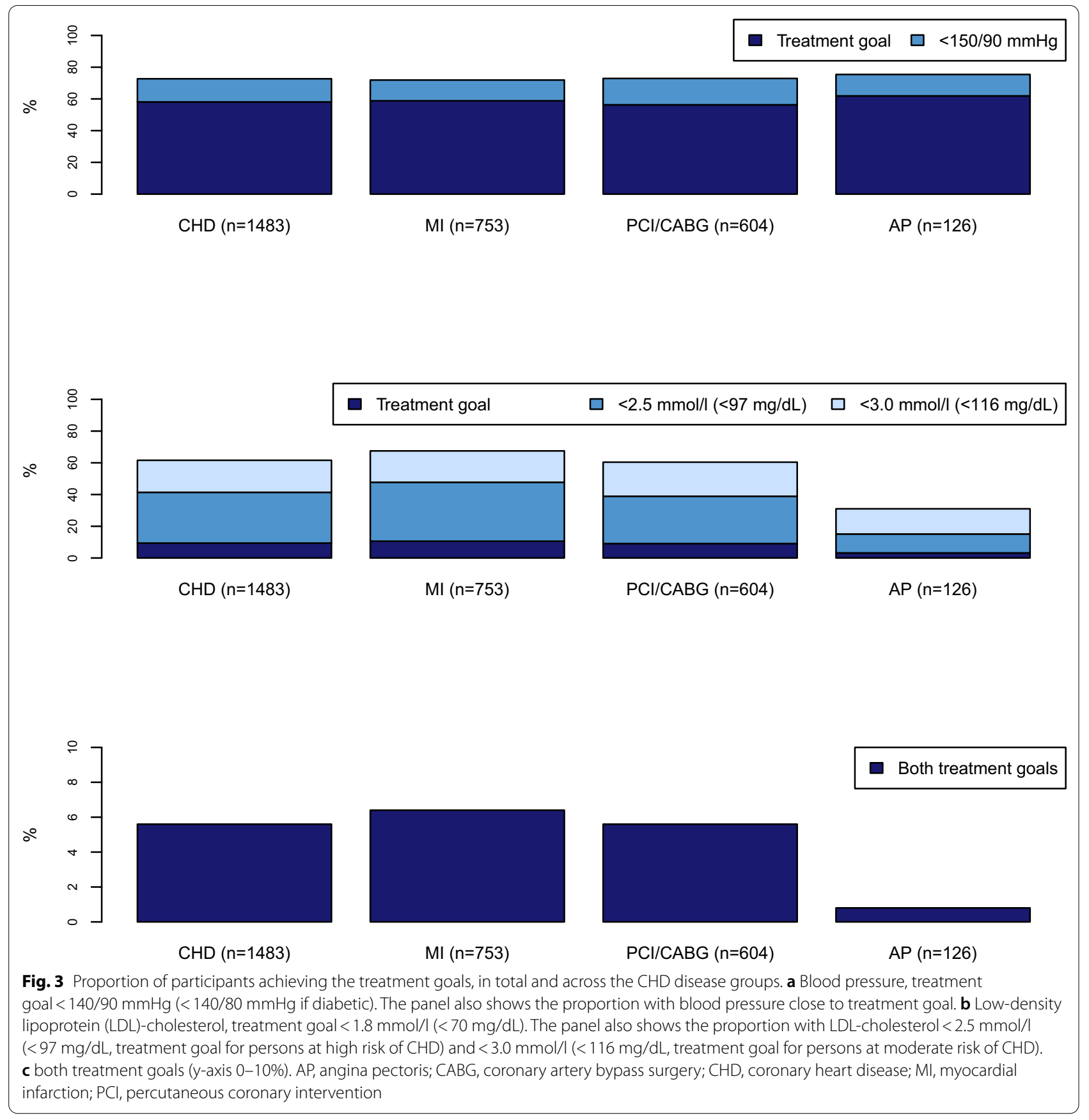

accordance with the guidelines, i.e. using ASA and LLDs and achieving both treatment goals. The proportion reaching both treatment goals was 9\% (62) among those who used all three classes of drugs and 3\% (21) among those who did not use all three $(p<0.001)$. Regarding CHD disease group, the proportion reaching both treatment goals was $6 \%$ (48) among those with a previous MI, 6\% (34) among those with PCI and/or CABG and $1 \%(1)$ among those with AP $(p=0.04)$. Characteristics of participants achieving and not achieving the recommended treatment goals for LDL-cholesterol and blood pressure among those using LLDs and antihypertensive drugs are shown in Table 3.

Among the participants with diabetes $(\mathrm{n}=214)$, $50 \%$ achieved the treatment goal for blood pressure $(<140 / 80 \mathrm{mmHg})$ and $14 \%$ for LDL-cholesterol $(<1.8 \mathrm{mmol} / \mathrm{L}$ or $<70 \mathrm{mg} / \mathrm{dL})$. Treatment goal for HbA1c $(<7 \%)$ was reached by $43 \%$ (for results on treatment goal 
Table 3 Characteristics of participants achieving and not achieving treatment goals among LLD and antihypertensive drug users

\begin{tabular}{|c|c|c|c|c|c|c|c|c|}
\hline \multirow{3}{*}{ Sex, n (\%) } & \multicolumn{4}{|c|}{$\begin{array}{l}\text { Users of LLDs } \\
(n=1133)\end{array}$} & \multicolumn{4}{|c|}{$\begin{array}{l}\text { Users of antihypertensive drugs among } \\
\text { participants with hypertension } \\
(\mathrm{n}=763)\end{array}$} \\
\hline & \multicolumn{2}{|c|}{$\begin{array}{l}\text { Achieving } \\
\text { LDL-goal } \\
(n=136)\end{array}$} & \multicolumn{2}{|c|}{$\begin{array}{l}\text { Not achieving LDL- } \\
\text { goal } \\
(\mathrm{n}=991)\end{array}$} & \multicolumn{2}{|c|}{$\begin{array}{l}\text { Achieving } \\
\text { BP-goal } \\
(\mathrm{n}=379)\end{array}$} & \multicolumn{2}{|c|}{$\begin{array}{l}\text { Not achieving } \\
\text { BP-goal } \\
\text { ( } n=382 \text { ) }\end{array}$} \\
\hline & & & & & & & & \\
\hline Women & 29 & $(21.3)$ & 262 & $(26.4)$ & 123 & (32.5) & 132 & (34.6) \\
\hline Age, mean (sd) & 69.7 & (9.5) & 69.4 & (9.8) & 68.0 & (9.7) & 71.6 & (9.6) \\
\hline \multicolumn{9}{|l|}{ Smoking, n (\%) } \\
\hline Daily smoking & 15 & $(11.0)$ & 114 & $(11.5)$ & 52 & (13.7) & 29 & $(7.5)$ \\
\hline Smoked previously & 79 & $(58.1)$ & 617 & $(62.3)$ & 218 & $(57.5)$ & 236 & $(61.8)$ \\
\hline \multicolumn{9}{|l|}{ Self-reported health, n (\%) } \\
\hline Excellent/good & 56 & $(41.2)$ & 478 & $(48.2)$ & 157 & $(41.4)$ & 161 & $(42.1)$ \\
\hline Neither good nor bad & 68 & $(50.0)$ & 403 & $(40.7)$ & 175 & $(46.2)$ & 177 & $(46.3)$ \\
\hline Bad/very bad & 9 & $(6.6)$ & 99 & $(10.0)$ & 44 & (11.6) & 40 & $(10.4)$ \\
\hline \multicolumn{9}{|l|}{ Comorbidities*, n (\%) } \\
\hline Heart failure & 20 & $(14.7)$ & 176 & $(17.8)$ & 72 & (19.0) & 65 & $(17.0)$ \\
\hline Atrial fibrillation & 23 & $(16.9)$ & 181 & $(18.3)$ & 84 & $(22.1)$ & 76 & $(19.9)$ \\
\hline Stroke & 12 & $(8.8)$ & 90 & $(9.1)$ & 45 & $(11.9)$ & 46 & $(12.0)$ \\
\hline Diabetes & 28 & $(20.6)$ & 147 & $(14.8)$ & 72 & $(19.0)$ & 74 & $(19.4)$ \\
\hline Renal disease & 7 & $(5.2)$ & 71 & $(7.1)$ & 25 & (6.6) & 40 & $(10.5)$ \\
\hline Cancer & 18 & $(13.2)$ & 124 & $(12.5)$ & 44 & (11.6) & 60 & $(15.8)$ \\
\hline Medications, mean number of products (sd) & 5.3 & (2.9) & 4.4 & $(2.8)$ & 5.0 & (2.9) & 5.0 & $(2.9)$ \\
\hline \multicolumn{9}{|l|}{ Clinical measurements, mean (sd) } \\
\hline Systolic blood pressure, mmHg & 133 & $(18.5)$ & 136 & $(21.0)$ & 123 & $(11.7)$ & 155 & $(15.4)$ \\
\hline Diastolic blood pressure, $\mathrm{mmHg}$ & 73 & $(9.2)$ & 74 & (9.8) & 71 & (8.5) & 79 & (9.6) \\
\hline Total cholesterol, $\mathrm{mmol} / \mathrm{l}^{\dagger}$ & 3.3 & $(0.6)$ & 4.5 & $(0.9)$ & 4.4 & $(1.0)$ & 4.6 & $(1.1)$ \\
\hline LDL-cholesterol, $\mathrm{mmol} / \mathrm{I}^{\dagger}$ & 1.5 & $(0.2)$ & 2.7 & $(0.8)$ & 2.7 & $(0.9)$ & 2.8 & $(1.0)$ \\
\hline $\mathrm{HDL}$-cholesterol, $\mathrm{mmol} / \mathrm{I}^{\dagger}$ & 1.5 & $(0.6)$ & 1.4 & $(0.4)$ & 1.4 & $(0.4)$ & 1.4 & $(0.4)$ \\
\hline Triglycerides, $\mathrm{mmol} / \mathrm{I}^{\ddagger}$ & 1.5 & (1.6) & 1.6 & $(0.9)$ & 1.7 & (0.9) & 1.7 & $(1.1)$ \\
\hline $\mathrm{HbA} 1 \mathrm{c}, \%$ & 6.3 & $(1.0)$ & 6.1 & $(0.9)$ & 6.1 & $(1.0)$ & 6.1 & $(1.0)$ \\
\hline Glucose, $\mathrm{mmol} / \mathrm{l}^{\S}$ & 6.5 & $(2.7)$ & 6.0 & $(2.1)$ & 6.2 & (2.3) & 6.2 & $(2.2)$ \\
\hline $\mathrm{BMI}, \mathrm{kg} / \mathrm{m}^{2}$ & 28.4 & $(4.6)$ & 28.4 & $(4.3)$ & 29.2 & (4.6) & 28.9 & $(4.4)$ \\
\hline
\end{tabular}

Percentages are calculated for columns

AP, angina pectoris; BMI, body mass index; BP, blood pressure; CABG, coronary artery bypass graft; $C H D$, coronary heart disease; HDL, high-density lipoprotein; LDL, low-density lipoprotein; LLD, lipid-lowering drugs; MI, myocardial infarction; PCl, percutaneous coronary intervention; sd, standard deviation

* Self-reported relevant comorbidities for coronary heart disease, present or previous diseases

${ }^{\dagger}$ To convert to $\mathrm{mg} / \mathrm{dL}$, multiply with 38.67

‡ To convert to $\mathrm{mg} / \mathrm{dL}$, multiply with 88.57

${ }^{\S}$ To convert to $\mathrm{mg} / \mathrm{dL}$, multiply with 18.02

achievement for HbA1c in the different CHD disease groups, see Additional file 1: Table S4). All three treatment goals were reached by $4 \%$.

Logistic regression with propensity score matching showed that use of LLDs was significantly associated with treatment goal achievement for LDL-cholesterol, while the use of antihypertensive drugs among participants with hypertension was not associated with treatment goal achievement for blood pressure, see Table 4 .
Results from the propensity score matching can be found in Additional file 1: Tables S5 and S6.

\section{Discussion}

We have identified that a relatively high proportion of persons with CHD adhere to the recommended prescription guidelines. However, fewer of the participants in our study use LLDs, antihypertensive drugs and ASA compared to what has been found in other studies $[7,8,18$, 
Table 4 Pooled results from the logistic regression analyses of the propensity score matched multiple imputed datasets

\begin{tabular}{llll}
\hline Exposure variable & Outcome variable & Odds ratio & $\begin{array}{l}\mathbf{9 5 \%} \\
\text { confidence } \\
\text { interval }\end{array}$ \\
\hline $\begin{array}{l}\text { Use of lipid-lowering } \\
\text { drugs }\end{array}$ & $\begin{array}{c}\text { Achievement of } \\
\text { treatment goal } \\
\text { for LDL-choles- } \\
\text { terol }\end{array}$ & 14.0 & $3.6-54.7$ \\
$\begin{array}{l}\text { Use of antihypertensive } \\
\text { drugs }\end{array}$ & $\begin{array}{l}\text { Achievement of } \\
\text { treatment goal } \\
\text { for blood pres- } \\
\text { sure }\end{array}$ & 1.3 & $0.7-2.6$ \\
\hline
\end{tabular}

Number of cases varied between datasets and can be found in Additional file 1: Tables S5 and S6

19]. The newest EUROASPIRE survey from 2019 found a proportion of use of $84 \%$ for LLDs, $95 \%$ for antihypertensive drugs and $93 \%$ for antiplatelet drugs [7]. The results from The NORwegian CORonary (NOR-COR) Prevention Study, STabilization of Atherosclerotic plaque By Initiation of darapLadIb TherapY (STABILITY) study and the prospeCtive observational LongitudinAl RegIstry oF patients with stable coronary arterY disease (CLARIFY) study are also similar to that of the EUROASPIRE $[8,18$, 19]. Unlike our study, most of these studies attain their information about medication use from medical journals and the studies are usually conducted within a limited time frame after discharge from the hospital. As far as we know, ours is the first study to focus on persons with $\mathrm{CHD}$ in a general population, independent of time since diagnosis, and to investigate the participants' own selfreported use of medications.

Compared with other studies, the use of ASA and other antiplatelet drugs in our study is especially low $[7,8,18$, 19]. The guidelines recommend use of ASA as secondary prevention for those who have had an MI, PCI or CABG, i.e., not including persons with only AP. In the current study, $70 \%$ within this subpopulation $(n=1357)$ used ASA, which is lower than what has been reported previously $[7,8]$. Including other antiplatelet drugs increased the proportion of users to $71 \%$, while the proportion of users of any antithrombotic drug (antiplatelets or anticoagulants) was $78 \%$. Although there will always be some who cannot use antithrombotics, this user prevalence is lower than expected.

Despite high prevalence of use of antihypertensive drugs and LLDs, achievement of treatment goals was low, especially for LDL-cholesterol. This is also comparable to what has been found in other studies, though the level of achievement for LDL-cholesterol was lower in our study $[7,8,20,21]$. Since our study population is defined as participants already having heart disease, they are considered to have a very high cardiovascular (CVD) risk, and the guidelines therefore recommend a treatment goal for LDL-cholesterol at $<1.8 \mathrm{mmol} / \mathrm{L}$ $(<70 \mathrm{mg} / \mathrm{dL})$ or a reduction of $\geq 50 \%$ for LDL-cholesterol when the target cannot be reached [6]. As this is a cross-sectional study, we do not know the participants' cholesterol levels at treatment initiation and are therefore not able to determine whether they have had a 50\% reduction in LDL-cholesterol. However, even when applying a threshold of $<3 \mathrm{mmol} / \mathrm{L}(<116 \mathrm{mg} / \mathrm{dL})$, only $62 \%$ achieve the treatment goal (Fig. $3 \mathrm{~b}$ ). This indicates that many participants were far from reaching the recommended treatment goal.

The proportion of participants using antihypertensive drugs and achieving the treatment goals for blood pressure was comparable to what has been found in other studies $[7-9,18,19]$. These studies do not however explore the relationship between the two. We did not find a statistically significant relationship between using antihypertensive drugs and achieving the treatment goal for blood pressure. One plausible explanation for this is that participants who had been prescribed antihypertensive drugs probably had a higher baseline blood pressure than those who were not prescribed antihypertensive drugs. If so, some of the participants using antihypertensive drugs may have experienced a reduction in blood pressure, though not enough to reach the recommended treatment goal. Non-adherence could also be a potential explanation why we do not detect a statistically significant difference in achievement of treatment goal between participants using and not using antihypertensive drugs. Another possibility is that our population is too small, as so few persons with hypertension were not using antihypertensive drugs. This affects the propensity score matching, and makes it difficult to achieve comparable groups that are similar enough on all variables used in the propensity score. Further studies using a larger hypertensive population is therefore needed to confirm these results.

Of the three CHD disease groups, persons with previous MI, PCI or CABG have a higher risk of new major coronary events and require a closer follow-up than persons with only self-reported AP. We found that among participants within the PCI or CABG group, fewer persons reached the treatment goals for both blood pressure and LDL-cholesterol and fewer of these persons used LLDs, antihypertensive drugs and ASA compared to those with previous MI (Figs. 2 and 3). This suggests that these persons need closer follow-up.

\section{Strengths and limitations}

We have used data from the Tromsø Study, a reliable population-based data source where measurements 
of blood pressure and cholesterol were performed by trained personnel and with standardized procedures and instruments. The Tromsø Study has a high attendance rate and is considered representative for an urban, white Northern European population [15].

Measurements of blood pressure and LDL-cholesterol were done objectively, which is also a strength of the study. So is the use of multiple imputation to avoid bias due to missing values and propensity score matching to control for confounding. Propensity score matching appropriately balances the covariates between treated and untreated participants and makes it possible to include more covariates than in a conventional multivariable logistic regression.

The major limitation in this study is that we do not have any information about blood pressure and LDLcholesterol at treatment initiation, which restricts us to investigating the participants' blood pressure and LDLcholesterol at the time of their attendance in Troms $\varnothing 7$.

We also lack information about the participants' medication adherence; hence we do not know if the participants actually take their medication as prescribed. Non-adherence is likely to reduce their achievement of treatment goals.

Another limitation of the study is that most variables are self-reported, including CHD diagnosis and use of medications. We may have underestimated adherence to treatment guidelines through inclusion of some participants that are not actual CHD patients, or exclusion of participants who did not recall a previous CHD event. Such misclassification is less likely for life threatening conditions like MI, and although there may be some who reported MI when they have had a PCI/CABG (or vice versa), the extent would be limited and should not noteworthy alter the study results. Self-reported medication use could make the results susceptible to recall bias. For medications used for chronic conditions such as CHD, self-reported use of medications have shown good to very good agreement with prescription data [22], suggesting that recall bias should be a minor problem in our study.

A disadvantage with the statistical methods is that propensity score matching does not use all the observations. This is especially a problem when the groups of treated and untreated are very unevenly distributed, as in our study population (76\% use LLDs and $92 \%$ of those with hypertension use antihypertensive drugs). To include as many observations as possible we performed matching with replacement. This procedure may introduce bias as several participants among medication users can be matched with the same non-user, and some may not be matched to anyone at all. However, a re-analysis without replacement gave very similar result, suggesting our results are valid (for results from this sensitivity analysis, see Additional file 1: Table S7). As propensity score matching only controls for measured confounders, our results might still be affected by unmeasured variables, which are only controllable through randomization.

\section{Conclusion}

Despite high adherence to prescription guidelines and a strong association between use of LLDs and treatment goal achievement, the proportion who reaches the treatment goals is low among persons with CHD in a general population. Further research should include longitudinal studies to explore dosage regimens and medication adherence among persons with CHD over time.

\section{Abbreviations}

ACE: Angiotensin converting enzyme; AP: Angina pectoris; ARB: Angiotensin receptor blocker; ASA: Acetylsalicylic acid; ATC: Anatomical therapeutic chemical; BMI: Body mass index; CABG: Coronary artery bypass surgery; CCB: Calcium channel blocker; CHD: Coronary heart disease; Cl: Confidence interval; CVD: Cardiovascular disease; EUROASPIRE: European survey of cardiovascular disease prevention and diabetes; HbA1c: Glycated haemoglobin; HDL: Highdensity lipoprotein; LDL: Low-density lipoprotein; LLD: Lipid-lowering drug; MI: Myocardial infarction; OR: Odds ratio; PCl: Percutaneous coronary intervention; SD: Standard deviation; SPSS: Statistical Package for the Social Sciences.

\section{Supplementary Information}

The online version contains supplementary material available at https://doi. org/10.1186/s12872-021-01866-1.

\begin{abstract}
Additional file 1: Table S1. Overview of ATC-codes included in the three medication categories recommended for CHD based on the European Society of Cardiology: Guidelines on cardiovascular disease prevention in clinical practice (version 2012) [6]. Table S2. Variables included as covariates in propensity score. Table S3. Variables included in multiple imputation. Table S4. Achievement of treatment goal for $\mathrm{HbA} 1 \mathrm{c}$ for participants with diabetes in the different CHD disease groups. Table S5. Results from propensity score matching of the ten imputed datasets for the logistic regression analysis of the association between use of lipid-lowering drugs and achieving the treatment goal for LDL-cholesterol. Table S6. Results from propensity score matching of the ten imputed datasets for the logistic regression analysis of the association between use of antihypertensive drugs and achieving the treatment goal for blood pressure among those with self-reported hypertension. Table S7. Pooled results from the sensitivity analysis for the logistic regression analyses of the multiple imputed datasets, using propensity score matching without replacement.
\end{abstract}

\section{Acknowledgements \\ We gratefully acknowledge the statistical assistance from Frode Skjold and Kristian Svendsen, and would also like to thank all participants in the Troms $\varnothing$ Study for their contributions. Preliminary results from this study have previ- ously been presented at the International Conference on Pharmacoepidemiol- ogy and Therapeutic Risk Management 2019, and the abstract was published in Pharmacoepidemiology and Drug Safety in August 2019 [23].}

\section{Authors' contributions}

$\mathrm{EP}, \mathrm{MW}, \mathrm{BHG}, \mathrm{KHH}, \mathrm{AEE}$ and $\mathrm{HS}$ contributed to the conception and/or design of the work. EP, AEE and HS contributed to the acquisition of data for the work. EP drafted the manuscript and conducted the analyses. All contributed to the interpretation of data and critically revised the manuscript. All gave final approval and agree to be accountable for all aspects of work ensuring integrity and accuracy. 


\section{Funding}

The authors received no specific funding for this work.

\section{Availability of data and materials}

The owner of the data is the Tromsø Study. We have permission to analyse the data according to the protocol submitted to the Tromsø Study; however, we do not have permission to share the data. Other interested researchers can request the data in the same manner if they comply with the requirements of the institution (https://en.uit.no/forskning/forskningsgrupper/sub?p_docum ent_id=453582\&sub_id=66 9706).

\section{Ethics approval and consent to participate}

The study was approved by the Norwegian Data Protection Authority and the Regional Committee for Medical and Health Research Ethics of North Norway (approval reference 2014/940 for Tromsø 7 and 2015/1775 for the current study). All participants in the Troms $\varnothing$ Study have given written informed consent for their data to be used in research.

\section{Consent for publication}

Not applicable.

\section{Competing interests}

The authors declare that they have no competing interests.

\section{Author details \\ 'Department of Pharmacy, UiT The Arctic University of Norway, Troms $\varnothing$, Norway. ${ }^{2}$ Department of Community Medicine, UiT The Arctic University of Norway, Troms $\varnothing$, Norway. ${ }^{3}$ Department of Cardiology, Akershus University Hospital, Lørenskog, Norway. ${ }^{4}$ Institute of Clinical Medicine Campus Ahus, University of Oslo, Oslo, Norway.}

Received: 26 August 2020 Accepted: 13 January 2021

Published online: 21 January 2021

\section{References}

1. Timmis A, Townsend N, Gale C, Grobbee R, Maniadakis N, Flather M, et al. European Society of Cardiology: cardiovascular disease statistics 2017. Eur Heart J. 2018;39(7):508-79.

2. Naghavi MAA, Abbafati $C$, et al. Global, regional, and national age-sex specific mortality for 264 causes of death, 1980-2016: a systematic analysis for the Global Burden of Disease Study 2016. Lancet (London, England). 2017;390(10100):1151-210.

3. Yusuf S, Hawken S, Ounpuu S, Dans T, Avezum A, Lanas F, et al. Effect of potentially modifiable risk factors associated with myocardial infarction in 52 countries (the INTERHEART study): case-control study. Lancet (London, England). 2004;364(9438):937-52.

4. Eggers KM, Hadziosmanovic N, Baron T, Hambraeus K, Jernberg T, Nordenskjold A, et al. Myocardial infarction with nonobstructive coronary arteries: the importance of achieving secondary prevention targets. Am J Med. 2018;131(5):524-31.e6.

5. Mannsverk J, Wilsgaard T, Mathiesen EB, Lochen ML, Rasmussen K, Thelle $D S$, et al. Trends in modifiable risk factors are associated with declining incidence of hospitalized and nonhospitalized acute coronary heart disease in a population. Circulation. 2016;133(1):74-81.

6. Perk J, De Backer G, Gohlke H, Graham I, Reiner Z, Verschuren M, et al. European Guidelines on cardiovascular disease prevention in clinical practice (version 2012). The Fifth Joint Task Force of the European Society of Cardiology and Other Societies on Cardiovascular Disease Prevention in Clinical Practice (constituted by representatives of nine societies and by invited experts). Eur Heart J. 2012;33(13):1635-701.

7. Kotseva K, De Backer G, De Bacquer D, Ryden L, Hoes A, Grobbee $D$, et al. Lifestyle and impact on cardiovascular risk factor control in coronary patients across 27 countries: results from the European Society of Cardiology ESC-EORP EUROASPIRE V registry. Eur J Prev Cardiol. 2019;26(8):824-35.
8. Sverre E, Peersen K, Husebye E, Gjertsen E, Gullestad L, Moum T, et al. Unfavourable risk factor control after coronary events in routine clinical practice. BMC Cardiovasc Disord. 2017;17(1):40.

9. Hopstock LA, Eggen AE, Lochen ML, Mathiesen EB, Nilsen A, Njolstad I, et al. Blood pressure target achievement and antihypertensive medication use in women and men after first-ever myocardial infarction: the Tromso Study 1994-2016. Open Heart. 2018;5(1):e000746.

10. Hopstock LA, Eggen AE, Lochen ML, Mathiesen EB, Njolstad I, Wilsgaard T. Secondary prevention care and effect: total and low-density lipoprotein cholesterol levels and lipid-lowering drug use in women and men after incident myocardial infarction-The Tromso Study 1994-2016. Eur J Cardiovasc Nurs. 2018. https://doi.org/10.1177/1474515118762541.

11. Hopstock LA, Bonaa KH, Eggen AE, Grimsgaard S, Jacobsen BK, Lochen $\mathrm{ML}$, et al. Longitudinal and secular trends in blood pressure among women and men in birth cohorts born between 1905 and 1977: the tromso study 1979 to 2008. Hypertension. 2015;66(3):496-501.

12. Hopstock LA, Bonaa KH, Eggen AE, Grimsgaard S, Jacobsen BK, Lochen $\mathrm{ML}$, et al. Longitudinal and secular trends in total cholesterol levels and impact of lipid-lowering drug use among Norwegian women and men born in 1905-1977 in the population-based Tromso Study 1979-2016. BMJ Open. 2017;7(8):e015001.

13. Kotseva K. The EUROASPIRE surveys: lessons learned in cardiovascular disease prevention. Cardiovasc Diagn Ther. 2017;7(6):633-9.

14. Jacobsen BK, Eggen AE, Mathiesen EB, Wilsgaard T, Njolstad I. Cohort profile: the Tromso Study. Int J Epidemiol. 2012;41(4):961-7.

15. Eggen AE, Mathiesen EB, Wilsgaard T, Jacobsen BK, Njolstad I. The sixth survey of the Tromso Study (Tromso 6) in 2007-08: collaborative research in the interface between clinical medicine and epidemiology: study objectives, design, data collection procedures, and attendance in a multipurpose population-based health survey. Scand J Public Health. 2013:41(1):65-80

16. The Troms $\varnothing$ Study. The seventh survey of the Troms $\varnothing$ Study [cited 2020 August 26]. https://en.uit.no/forskning/forskningsgrupper/sub?p_docum ent_id=453582\&sub_id $=453680$.

17. Berg C. Reseptregisteret 2013-2017 [The Norwegian Prescription Database 2013-2017] Legemiddelstatistikk 2018:2. Oslo, Norway; 2018.

18. Vedin O, Hagstrom E, Stewart R, Brown R, Krug-Gourley S, Davies R, et al. Secondary prevention and risk factor target achievement in a global, high-risk population with established coronary heart disease: baseline results from the STABILITY study. Eur J Prev Cardiol. 2012;20(4):678-85.

19. Ferrari R, Ford I, Greenlaw N, Tardif JC, Tendera M, Abergel H, et al. Geographical variations in the prevalence and management of cardiovascular risk factors in outpatients with CAD: Data from the contemporary CLARIFY registry. Eur J Prev Cardiol. 2015;22(8):1056-65.

20. Munkhaugen J, Sverre E, Otterstad JE, Peersen K, Gjertsen E, Perk J, et al. Medical and psychosocial factors and unfavourable low-density lipoprotein cholesterol control in coronary patients. Eur J Prev Cardiol. 2017;24(9):981-9.

21. Gjelsvik B, Tran AT, Berg TJ, Bakke A, Mdala I, Nokleby K, et al. Exploring the relationship between coronary heart disease and type 2 diabetes: a crosssectional study of secondary prevention among diabetes patients. BJGP Open. 2019;3(1):101636.

22. Nielsen MW, Sondergaard B, Kjoller M, Hansen EH. Agreement between self-reported data on medicine use and prescription records vary according to method of analysis and therapeutic group. J Clin Epidemiol. 2008;61(9):919-24.

23. Pedersen E, Garcia BH, Eggen AE, Halvorsen $\mathrm{KH}$, Schirmer $\mathrm{H}$, Waaseth $\mathrm{M}$ Adherence to prescription guidelines and achievement of treatment goals among persons with coronary heart disease: a cross-sectional study. Pharmacoepidemiol Drug Saf. 2019;28(S2):5-586.

\section{Publisher's Note}

Springer Nature remains neutral with regard to jurisdictional claims in published maps and institutional affiliations. 